Article

\title{
Mapping European Border Control: On Small Maps, Reflexive Inversion and Interference
}

\author{
Silvan Pollozek \\ Digital Media Lab, Munich Centre for Technology in Society, Technical University of Munich, 80333 Munich, Germany; \\ E-Mail: silvan.pollozek@tum.de
}

Submitted: 15 June 2020 | Accepted: 7 September 2020 | Published: 19 November 2020

\begin{abstract}
The so-called hotspots-identification and registration centres on the Aegean Islands in Greece and in Italy-are not only sites of remote detention, European intervention or differential inclusion, but also logistical set-ups, where data is generated and spread across state institutions. Such socio-technical assemblages are hard to research not only because of state actors' desire to keep things secret but also because of methodological issues. How does one disentangle their extensive, complex and rhizomatic nature? Which trajectories does one follow and which actors and voices does one assemble? Following recent work in the realm of STS, methods are understood as (b)ordering devices, which performatively enact an ordered world and produce accounts of the social, including some realities while excluding others. This article considers mapping a well-suited method for studying widespread socio-technical assemblages, but only if it is handled with caution. Based on an empirical inquiry into the Moria hotspot and following a praxeographic research approach, different types of small maps are developed that enfold complexity by being attentive to situatedness, symmetry, multi-sitedness and multiplicity. Furthermore, it emphasizes an on-going process of reflexive inversion of the mapping process that makes the crafted accounts contestable and its boundaries and blind spots visible. Finally, the article discusses how mappings can be used not only as research but also as a political device that contributes to the work of other collectives beyond the scientific production of truth.
\end{abstract}

\section{Keywords}

issue maps; methods as ordering device; Moria hotspot; praxeography; situational maps; social world maps; trajectory maps

Issue

This article is part of the issue "Method as Border: Articulating 'Inclusion/Exclusion' as an Academic Concern in Migration and Border Research in Europe" edited by Kolar Aparna (Radboud University, The Netherlands), Joris Schapendonk (Radboud University, The Netherlands) and Cesar Merlín-Escorza (Radboud University, The Netherlands).

(C) 2020 by the author; licensee Cogitatio (Lisbon, Portugal). This article is licensed under a Creative Commons Attribution 4.0 International License (CC BY).

\section{Introduction}

The so-called hotspots-identification and registration centres in the Aegean Islands in Greece and Italy-are not only sites of detention (Dimitriadi, 2017), European intervention (Kuster \& Tsianos, 2016) or sorting centres (Campesi, 2018), but also logistical set-ups where data is generated, inserted into different chains and spread across state institutions (Pollozek \& Passoth, 2019). Such socio-technical assemblages of migration and border control are hard to research not only because of several strategies that attempt to keep things secret or hidden but also because of methodological issues. Considering the number of agencies and their representatives, the many different forms and databases and the many sites and phenomena that are also related to the 'hotspot approach,' the question arises concerning how to study such an extensive, complex and rhizomatic subject. Following recent work in the realm of STS, methods are understood as (b)ordering devices which performatively enact an ordered social world and produce accounts of the social, as well as its components and attributes (Law \& Ruppert, 2013). As such, some (partial) realities, actors and problems are made present while 
others are made absent. Which trajectories does one follow and which actors and voices does one assemble?

This article considers mapping a well-suited method for studying geographically widespread and temporally fluid socio-technical assemblages and for drawing multiple actors, issues and materialities together (Dalton \& Mason-Deese, 2012, p. 445), but only if it is handled with caution and situated into a reflexive ethnographic research approach. Instead of crafting big maps that turn complex phenomena into simple schemes, silence voices, and produce matters of regulation or surveillance, this article opts for creating many small maps that enfold complexity by being attentive to situatedness, symmetry, multi-sitedness, and multiplicity. In the following, the article develops a mapping approach that is able to disentangle the extensive, complex and rhizomatic nature of migration and border control assemblages while at the same time being reflexive about how mapping performatively orders the social, navigates through a complex field, orchestrates voices and opens up realities for interventions. With this genuine focus on methodology and methods, the article aims to contribute to the current discourse on migration infrastructures and digital migration at the intersection of STS and critical migration and border studies.

Starting with a critique on a large map of the hotspot approach, this article will outline a small map approach that uses Adele Clarke's cartographic approaches as a starting point but pushes them towards a praxeographic methodology that focuses even more strongly on sociotechnical practices as well as on situated, processual and multiple becomings of human and non-human entities and orderings (Mol, 2002). Based on an ethnographic inquiry of the Moria hotspot on Lesvos between 2016 and 2018, this article will sketch out different mapping approaches-situational, social world, trajectory and issue mapping. In an on-going process of reflexive inversion, it will make the boundaries of the mapping processes visible, criticize their orderings and use the blind spots they produce for (re)directing the subsequent research process. In the end, the article will ask how mappings can be used not only as research but also as a political device that contributes to the work of other collectives beyond the scientific production of truth (Law, 2004).

\section{Situating Mapping in Praxeographic Research}

In July 2015, the EU Commission released an explanatory note to the hotspot approach, which had been introduced in the context of the EU Commission's European Agenda on Migration two months earlier. The explanatory note gives details about what a hotspot is, how coordination takes place on the ground, what kind of support could be provided and what "added value" the hotspot approach could have (EU Commission, 2015, p. 5). Additionally, it introduces "two roadmaps on the practical implications" sketching out "who is doing what"
(EU Commission, 2015, p. 10) and one 'hotspot approach' flowchart (Figure 1). The flowchart especially has been picked up by media (e.g., Der Standard), political (e.g., House of Lords) and EU actors (e.g., European Court of Auditors) because it was the only document back then that produced a first picture of the architecture of a hotspot with its actors, procedures and components.

This map brings together several actors in boxes via unilateral arrows that lead from one beginning to several ends. Even a first grasp of the map makes obvious that the bordering of migrant subjects is accomplished by a heterogeneous set-up shaped by such disparate things as agencies (Europol, Frontex, EASO), databases and technical systems (Eurodac), policies and measures (Consolidated version of the Treaty on the Functioning of the European Union, 2007, Art. 78[3]), practices (debriefing, registration/identification, refusal of fingerprinting, risk analysis), further procedures and locations (detention, relocation, return, transfer, etc.), responsibilities (member state [MS]) and switching points ("wish to apply for asylum-yes/no").

The ends of this map show various mechanisms of social sorting and both inclusion and exclusion ranging from "grant of international protection" to "relocation" to the "transfer to responsible MS" or "return." We can say that these different institutional tracks also differ due to the rights and entitlements migrants have concerning residency, housing, health, education, work and other social services. In this sense, the hotspot approach produces many different variations and graduations of migrants' status, which is characteristic of contemporary border regimes and termed differential inclusion (Mezzadra \& Neilson, 2013).

The map also makes us realize that bordering manifests not only in the camp but also "elsewhere," for instance in the Eurodac database or at the headquarters of Frontex and Europol. Recent work in the realm of science and technology studies has pointed to the distributed activities of listing, labelling and categorizing within institutional ecologies and to the technical mediations concerning remote surveillance and control through interconnected and meshed up databases (Dijstelbloem \& Broeders, 2015).

More than anything, the map produces a normative account of how things should work in this very organizational setup. It enacts an idealization of one big procedure which appears as functioning and seamless without frictions. Each actor has its role, the collaboration between organizations is defined, databases, organizations and humans are intertwined, and all procedures are lawful. It favours a clean technocratic solution that leaves out messiness, suffering, human rights and other issues-complexity. With this map circulating among policy and security actors, a powerful version of the hotspot approach has been enacted.

Latour $(2005$, p. 187) terms such maps panoramas. Panoramas see everything and nothing "since they simply show an image painted (or projected) on the tiny wall 


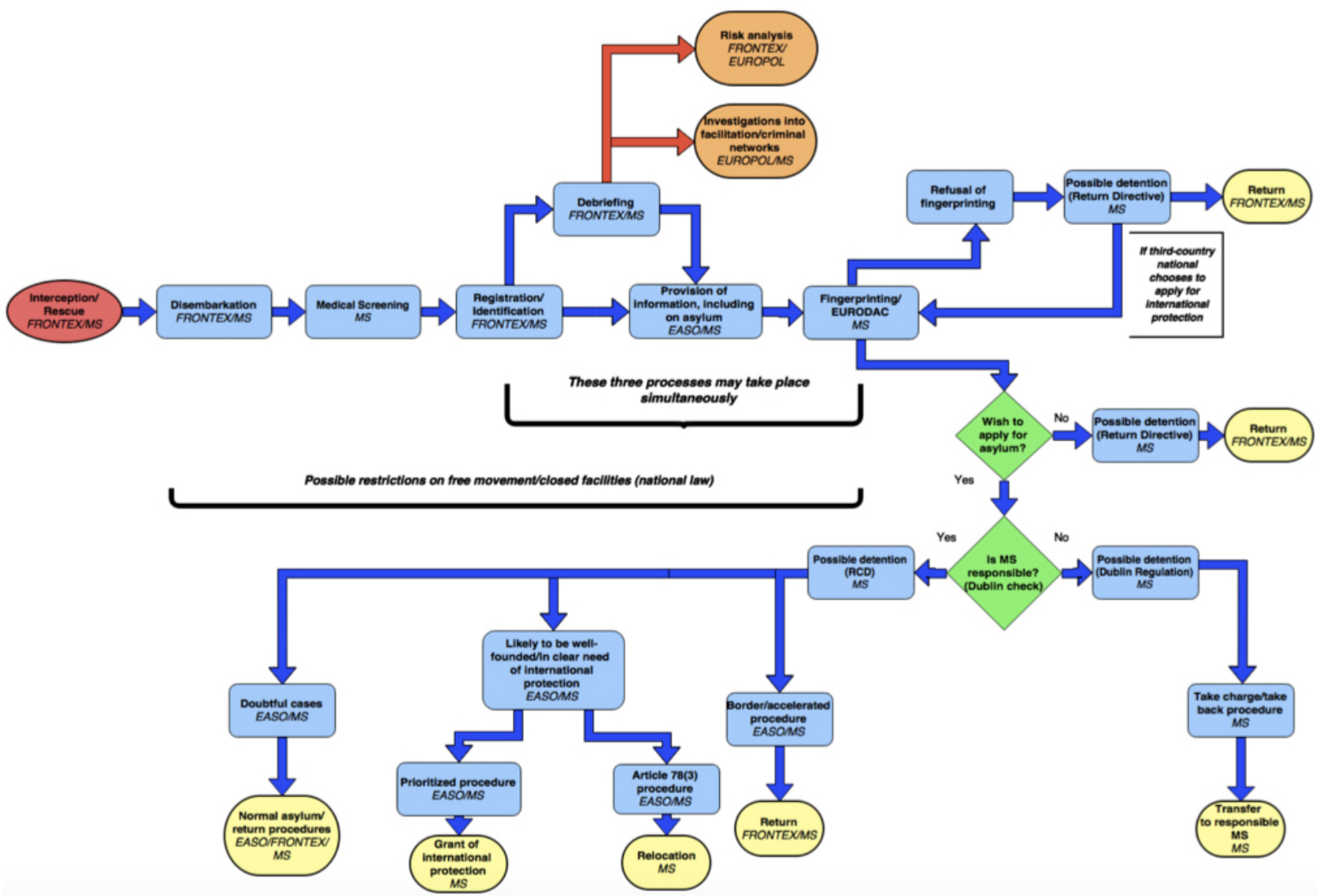

Figure 1. Hotspot approach. Source: EU Commission (2015, p. 12).

of a room fully closed to the outside." Panoramas do not make explicit how, by whom and for which purposes they were crafted. They either produce a distant position and simulate an "Archimedean point from which to represent the world" (Clifford, 1986, p. 22), or they enact a god-like view from no-where (Haraway, 1988). They turn a complex ecology into one simple scheme that represents the former "as a whole" - which is only possible by silencing many other voices and accounts (Geertz, 1973).

Panoramas also transform many phenomena, experiences and stories of people into numbers, populations, trends or other aggregates and translate them into matters of surveillance, control or regulation. In this sense, such maps refer to a practice strongly institutionalized by state actors and contribute to their stabilization and legitimization (Halder \& Michel, 2019, p. 13). They are a crucial political technology for the creation of 'situational awareness,' the drawing of future scenarios, and the articulation of governance problems (Tazzioli, 2018), and facilitate the institutionalization of (trans)national spaces of border surveillance (Hess, 2010). In order to subvert and criticize such oversimplified big maps and to decompose the n-way nature of socio-technical assemblages (Star \& Griesemer, 1989, p. 389), this article suggests an approach of counter-mapping that is based on 'thick analyses' and the creation of various 'small' maps, that aims to assemble multiple accounts of and voices in a situation of concern, and that is especially sensitive to silenced, invisibilized or othered voices and positions and to "what seems present but [remains] unarticulated" (Clarke, 2003, p. 561).

Especially for studying wide-spread and complex socio-technical assemblages of border control, this article suggests situating mapping into praxeographic research. As a variant of ethnography, praxeographic research focuses on situations but, by studying human and non-human entities in interaction and in a symmetrical way, it is more explicitly concerned with the sociomateriality and socio-technicality of a phenomenon. Meanings and identities are relevant regarding their effects on a particular practice as well as to the shaping of an entity or a social order (Sørensen \& Schank, 2017, p. 412). Furthermore, praxeography not only traces multiple perspectives on a phenomenon but also studies the becoming of multiple phenomena realized by various enactments (Mol, 1999). An empirical inquiry thus makes multiple conditions of possibility visible, traces multiple configurations, agencies and options of an entity, and analyses how those multiple becomings are related to each other (Knecht, 2013, p. 95).

Mapping as a praxeographic methods device thus needs to be attentive not only to situatedness, complexity, and multi-sitedness, but also to heterogeneity, multiplicity, and translation. But how does one translate this into a research practice of and with mapping? Maybe Adele Clarke's cartographic approaches 
are a promising starting point (Göde, 2015). Drawing on Strauss's social worlds and arena theory rooted in symbolic interactionist sociology and pragmatist philosophy, as well as on poststructuralist and postmodern approaches, Clarke has developed three types of mapping: (1) situational maps that empirically specify the elements of a situation-such as human and non-human actors, artefacts, objects, devices, doings, and sayingsas well as the relations among all the elements that "make each other up and together constitute the situation as a whole" (Clarke, 2019, p. 14); (2) social world maps that sketch out the social worlds coming together in a situation of interest, identify their properties, constraints, and resources, and make their intersections visible (Clarke, 2005, p. 110)-such maps lay out those collective actors and those lines of force that weigh on a situation, as well as those actors who are marginalized, silenced, or 'atomized,' without a collective; (3) positional maps that again carve out all the concerns articulated within a situation of concern, as well as those that have not been articulated but ignored, silenced or invisibilized.

Situational, social worlds and positional maps are very helpful approaches for opening up various situations of the trans-local and inter-organizational ordering of the hotspot. However, to be used as a praxeographic methods device that strictly focuses on practice, situatedness, heterogeneity, and multiplicity, they have to be modified in several ways: First, while Clarke seems to use situational maps for mapping a broader field of research, e.g., a broad institutional ecology of a hospital, a praxeography understands situations as confined events that (only) emerge when human and non-human entities actually meet and when meanings, knowledge, subjects, objects, and more are (re)enacted (Mathar, 2008, p. 31). In this sense, studying a wide-spread socio-technical assemblage praxeographically would mean conducting a small-range analysis and crafting maps on several situations in which entities meet.

Second, Mathar (2010, p. 157) criticizes how Clarke translates relationality into the mapping approaches. Clarke recommends putting all the entities on a piece of paper and then starting a relational analysis, in other words, to draw and qualify lines between the entities. This, however, risks producing immobile and essentialized entities, which stands against an actor-network theory-informed praxeography. Instead, research should shed light on the multiple becoming of an entity from situation to situation and be attentive to the processual shaping through time (Sørensen \& Schank, 2017, p. 412). This does not only imply crafting many maps that make the different enactments of entities visible but also creating inversions of the very maps that question and subvert the mapping of entities and their relations to each other.

Third, Clarke's cartographic approaches remain inattentive to the circulation of entities. Studying a translocal and inter-organizational socio-technical assemblage with various interconnected situations implies trac- ing the circulation of data, people and documents across various workplaces. Latour and others have criticized to think of the circulation of texts, figures, probes, goods, or other things from one site to another as a seamless and frictionless flow. Instead, when particular mediators have to move through time and space or when they bring their own agendas in, there are translation processes at work which alter the circulating entities in question. Callon (1984) has pointed to this with his subtle plays on the words 'traduction' and 'trahison' and argues that translation and betrayal are two sides of the same coin. In this sense, this article will develop trajectory maps that make visible the circulation of entities as well as reflect upon the transformations, tensions and frictions they go through.

Fourth, in contrast to Clarke's approaches that think of mapping as a mere research device, this article takes the political implications of mapping more strongly into account. In researching on and writing about the world, researchers interfere with the world they study (Law \& Singleton, 2013, p. 488). Researchers in the realm of STS have experimented with different formats of interference that seek to bring alternative issues and solutions into the field of research which have not been taken into account before (Niewöhner, 2016). Here, intervention is not understood as a normative operation in the sense that the researcher prioritizes and selects some possibilities while silencing or ignoring others (Sørensen \& Schank, 2017). Instead, by working out multiple enactments of subjects, objects and phenomena and the relations among them, an intervention would aim to complexify the normativity and power relations and point to alternative configurations. Similarly, and by drawing on Deleuze (1986), Pickles (2004) thinks mapping as a practice of enacting new possibilities and other realities that follows a logic of 'and, and, and.' Following such work, this article stresses to reflect upon the politics of mapping and to think about how mapping can be related to other social worlds and doings, forge new alliances, and create new collectives (Dalton \& Mason-Deese, 2012).

With these modifications in mind, mapping may become a suitable praxeographic methods device that helps to navigate through difficult terrain, to order a complex landscape of a socio-technical assemblage, and to trace the trajectories from one situation to another. At the same time, it represents the field's messiness, contradictions and heterogeneities, and urges us to reflect upon the research process as well as its politics. In the following, the article will return to the Moria hotspot and sketch out several mapping approaches that, together, seek to disentangle the socio-technical assemblage of the Moria hotspot.

\section{Mapping Bureaucratic Practices, Their Interrelations and Alterations: Situational Maps}

Situational maps aim to empirically specify the elements of a situation-such as human and non-human actors, 
artefacts, objects, devices, doings and sayings-as well as the relationalities among them (Clarke, 2019, p. 14). One of the great strengths of situational maps is that they direct the researcher to specific, located and situated accounts without referring to a context or a structure that would frame or explain situations. The researcher needs to find out which boundaries, contexts and conditions of a situation are created within the situation itself.

In the first year of my empirical inquiry, it was difficult to map the practices, and their actor-networks, of the Moria hotspot, because I was not allowed to access the camp. In the three weeks of my stay in Lesvos in November 2016, I managed to conduct fifteen interviews with Frontex officers, interpreters, personnel from UNHCR, Médicins du Monde (MdM), and the Hellenic Registration and Identification Service (RIS), as well with the commander of the camp. As I was not able to act as an ethnographer myself, I attempted to make my interlocutors the ethnographers of their own work. The creation of situational maps supported this process. I decided not only to craft maps by myself as part of the analysis of the interview afterwards, but also to use it as an interaction device: I created maps on large sheets of paper together with my interlocutors during the interview. While asking my interlocutors many questionsabout their daily work, which materials and devices they use, how they use it, which data they gather and process, with whom they interact and in which way, which problems and challenges they face, or which concerns they have-I tried to translate what they were saying onto a map. Such maps focused on what kind of practices the interlocutor conducted, where the doings took place, which human and nonhuman actors were involved, and which actions followed on which actions.

Often, the interlocutors were astonished about the complex working arrangements taking shape on the piece of paper, which turned the boring little doings into an interesting subject of inquiry, as well as into a matter of expertise. The situational maps also reminded both the researcher and the interlocutor to stay focused on the situated practices and not to get lost in general evaluations about the hotspots. The white spots and isolated entities on the paper also directed the course of the interview. It also happened that the interlocutors showed some photos and working devices in order to produce a better picture of how things work. After the interviews, I crafted new maps based on an in-depth analysis of the interviews, on additional working materials, and on the preliminary field maps. In an iterative process, this mapping exercise placed the doings and interactions of my interlocutors at Moria hotspot on paper, as well as all the other human and non-human entities they were working with.

Step by step, a number of situations can be carved out that are constitutive for the socio-technical assemblage of Moria hotspot (Figure 2): the practice of screening with screeners, interpreters and document specialists (ALDOs), identification manuals and Google Maps (III),

(II) ,the big tent"

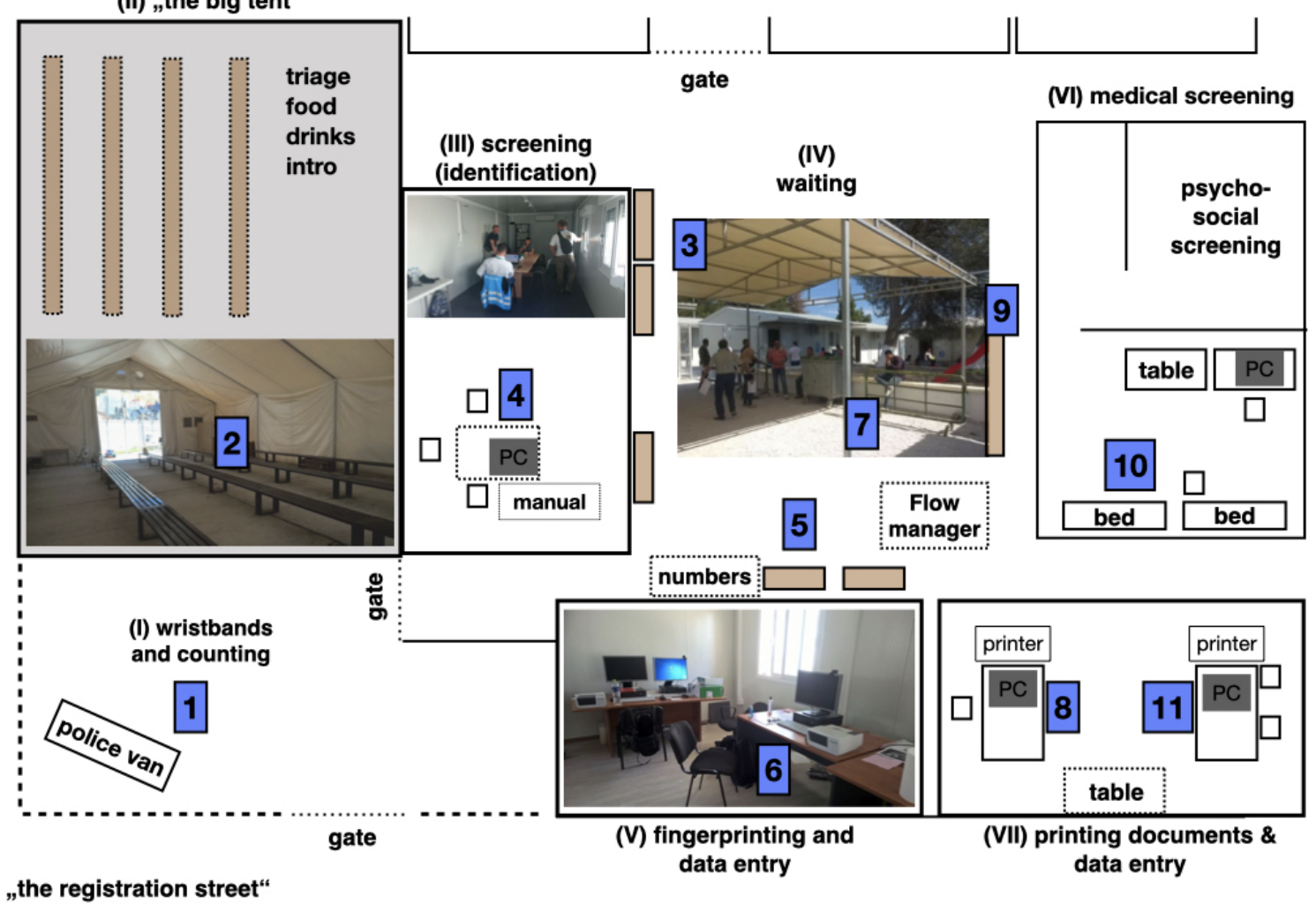

Figure 2. Situational map of the Registration and Identification Centre Moria. 
the practice of fingerprinting with fingerprinters, fingerprinting machines, police databases, Eurodac, and disinfectants (V), or the practice of issuing documents with computers, printing machines, stamps and clerks from Hellenic administrations (VII) (see, for an in-depth analysis, Pollozek \& Passoth, 2019). The situational maps also made visible the spatial organization of the Moria hotspot. The practices of screening, fingerprinting or issuing documents are contained through containers and separated from each other. They host highly stabilized and immobile entities, highly routinised practices, and a particular area of expertise. As we will see, each container accommodates a social world on its own. In contrast to those contained and immobile entities and practices, so-called "flow managers," the arrival and all kinds of documents move from one container to another.

While the interlocutors were able to provide differentiated and detailed descriptions about their working routines in their own container, they changed to a much more general and abstract register when I asked about the practices in the other containers. Then, regularly, the account of the "registration street" came into play (Pollozek \& Passoth, 2019). It basically describes how the so-called "irregular migrant" turns into a legalized person by going through different steps and stations. It is a well-structured and systematized story about a well-ordered procedure, and it reminded me of a text from a standard-procedure protocol. In the beginning, I was disappointed by such generalized descriptions until I noticed that it is an important device for the interlocutors to situate themselves within the bigger and spatially dispersed assemblage of the hotspot. While the "registration street" interrelates the spatialised and contained practices, it separates them from each other at the same time. It provides the basic roles of each actor in "the whole process" and articulates a teleological process and a technocratic procedure that provides so-called "irregular migrants" with legal status.

With situational mapping, the assemblage of the Moria hotspot has been decomposed into several different practices and actor-networks that are organizationally and spatially modularized, contained, and separated from each other. However, situational maps tend to insinuate a built, stabile and atemporal order. As praxeographic research takes the on-going enactment of reality into account (Law, 2004, p. 56), the researcher has to be attentive to the processuality of becoming and to the events that produce alterations and variations (Mol, 2002, p. 14). In this regard, I asked the interlocutors about changes, variations and reconfigurations and crafted several situational maps throughout my later fieldwork at the Hellenic Coast Guard, the international coordination centre (ICC) and the EU regional task force coordination centre (EURTF) in Piraeus in January and May 2017, at the Frontex headquarters in Warsaw in May 2017, at the local coordination centre (LCC), the Hellenic coast guard and Hellenic police departments, as well as at the Moria hotspot on Lesvos in April 2018. The mate- rial I gathered included another thirty interviews, several working documents and forms, and notes about several visits at the Moria hotspot facility.

Such maps crafted over time point to the on-going reconstructions and changes at the Moria hotspot. The workplaces in the containers both increased and decreased over the years, the staff was exchanged every month, agencies, such as MdM, withdraw, and the command went from the Hellenic Police to the RIS. There were also on-going ad-hoc reconstructions of the camp. The "big tent" of the camp, for example, was regularly used as a temporary sleeping facility, when too many people arrived on Lesvos' shores at the same time (Figure 2). It also happened that the whole centre was overcrowded and the gate between the tent and the "registration street" was unlocked, or that the yard turned into a playground, sleeping area or work ground. Sometimes, there was a "flow manager" at the Moria hotspot, other times, the process was organized by assigning numbers, or the officers would stand in front of the containers and call out names, and sometimes none of that happened. It also happened that the working stations were set up in front of the containers.

One could describe such observations as constant overflows that exceed the socio-material framing of the situations of screening, fingerprinting or document issuing (Callon, 1998). But, as other work also suggests, this may also be seen as a mode of governance at the camp, which Papada, Papoutsi, Painter, and Vradis (2019) termed "pop-up governance," and which can be characterized by tinkering, workarounds and shortterms solutions including improvised bureaucratic practices that are full of errors, inconsistencies and inaccuracies (Rozakou, 2017, p. 38). Although this is beyond the scope of this article, it would be worth elaborating on such ad-hoc and all too often irregular bureaucratic practices as a mode of statecraft carried out on the shoulders of migrants who face unbearable conditions with long waiting times and inadequate health, food, housing and other services.

\section{Studying Collectives, the Tensions between Them, and the Atomized Actors They Produce: Social World Maps}

While crafting situational maps, I was confronted with many different agencies and administrations. In contrast to accounts of a well-oiled machinery or a smooth multiactor collaboration found in policy documents, those collective actors, along with their representatives, agendas, resources, and funding and reporting schemes produced frictions and tensions in various ways.

Clarke aims to analyse the impact of collective actors on situations through social world maps and to carefully study their mutual interferences and entanglements. As outlined above, the registration and identification centre assembles several containers accommodating particular actor-networks and practices. Each container pro- 
duces organizational boundaries and hosts experts with particular knowledge who face particular problems and use particular devices. While screening and fingerprinting is conducted by Frontex and the medical screening is done by MdM, issuing documents is carried out by Hellenic administrations, namely the RIS and the Hellenic Police. Each of the practices is supported and carried out by a particular collective actor that again has the resources to assemble a whole collective of human and non-human actors, such as personnel, team leaders, coordinators, shift-plans, working equipment, computers, databases, devices, formulas, etc. and to push forward particular agendas (Figure 3).

Such different, and quite autonomous, social worlds distributed among different containers clashed with the official, hierarchical scheme of the Moria hotspot with the Hellenic authorities in charge and prevented its implementation. For Frontex, for instance, identifying and registering all people systematically and monitoring the data upload onto the Eurodac database is of utmost importance. It is a crucial part of genuine European migration management based on the Schengen agreement. This requires a thorough identification, which takes time and clashed at times with the agenda of the Hellenic police. The latter wanted to speed up the identification and registration procedures to clear the overcrowded centre. In the end, Frontex officers refused to accelerate the practice of identification and registration. MdM again felt quite uncomfortable with its role as a state actor and issuing health and vulnerability records. It tried to subvert its position and staged itself as a critical actor by publishing weekly reports on the situation in the Moria hotspot. Tensions between the agencies were additionally fuelled by unequal working conditions (Rozakou, 2017). Frontex officers, for example, received both a higher salary than local Hellenic police officers and better compensation for overtime hours.

Social world maps also make explicit what Clarke (2005, p. 46) calls "atomized" and "implicated actors" those who are not part of a social world, who have no collective behind them, no resources they can rely on, and no allies in whose name they can speak. Indeed, the arrivals running through the "registration street" are put in highly asymmetrical situations, in which they have only little to mobilize. However, from an angle of praxeography, such an analysis is too one-dimensional. This is because such a mapping shows neither in what ways atomized actors are plugged into social worlds differently nor how those atomized actors are enacted and made productive in multiple ways. In the case of the "registration street," a praxeographic analysis reveals that it is not a single actor but a 'human multiple' with several bodies, (data) identities, and subjectivities that are enacted. In the end, a legalized, migrant subject is crafted, but as a result of a cumulative process of enactments.

In the screening procedure, the arrival has to reveal biographical information about herself and convince the officers that such information is credible and that she

\section{Overall command: Hellenic Registration and Identification Service (RIS)}

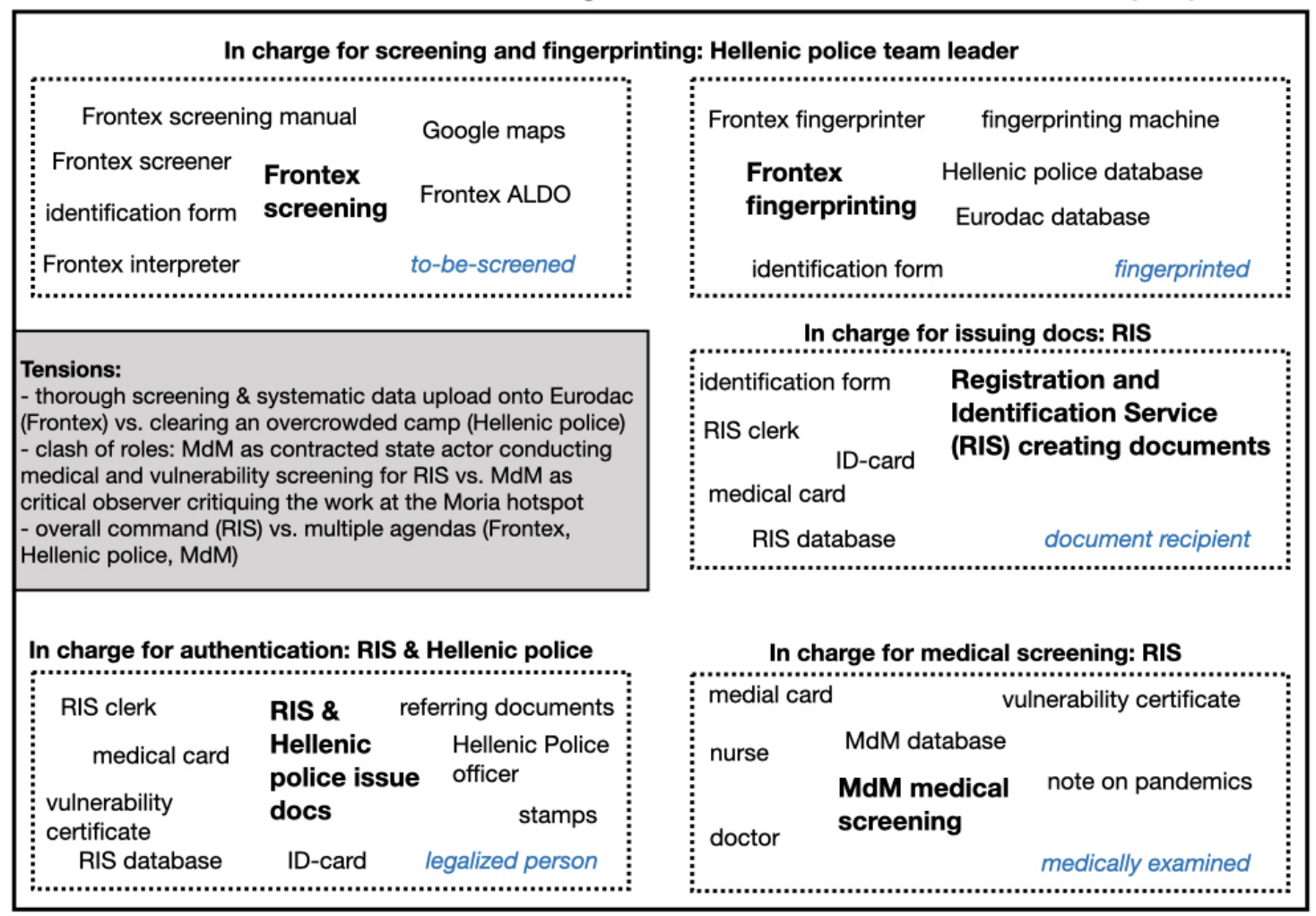

Figure 3. Social world map of the Registration and Identification Centre Moria. 
acts truthfully. Her stories about herself are checked in terms of consistency, locations are checked via Google Maps, her dialect is assessed by the interpreters and her body is approached as a telling entity that may reveal lies. In the end, an identity is defined by the screeners and stabilized in the "identification form." In the fingerprinting container, the hands and fingers serve as an identification device that makes it possible to create a legible identity without the need for an intelligible subject (Kuster \& Tsianos, 2012). Together with the classifications from the identification form, two more identities are created: one in the Hellenic police and another in the Eurodac database. In the medical screening, nurses and doctors approach the arrival in terms of mental and physical illness. Certificates, as well as the arrival's body, serve as a guarantor for the arrival's accounts. In the end, the doctors make a diagnosis and create two more identities, one about the health status of the arrival and another about whether she is vulnerable or not. Finally, RIS and Hellenic police produce a legal and stamped ID card that turns the arrival into a legalized entity with particular rights (social services, permit to stay on the island for a limited time) as well as many limitations.

Those multiple enactments of data identities will have their own social life in the different realms of EU and Hellenic administration (Pollozek \& Passoth, 2019). Yet, the multiple enactments are also put together in a cumulative and sequenced process that creates a legal entity-a legalized migrant subject-with particular characteristics in the end. As far as I have witnessed, neither the production of multiple identities nor what they are for and which consequences they could have to the person in question is explained properly at the site. There is no spokesperson for the arrival in the very procedures that could guide and advise her. And there is no office in the centre for objections, demands or requests. In other words, the politics of identification and registration is based on multiple enactments and their concealment.

\section{Tracing the Circulation of Forms and the Failures of Translation: Trajectory Maps}

With the situational maps and the social world maps, I was able to work out the particularities of several practices and their socio-material arrangements being at work at the Moria RIC, as well as how they are shaped by collective actors and collectives. Yet, how collaboration across the different situations and containers is realized has remained underexposed thus far. As Latour (2005) and others from the realm of actor-network theory have pointed out, trajectories cannot be taken for granted. Instead, it has to be studied how actors are capable of pointing to other localities, actors and points of time in the past and the future in their present work and which actors are successfully able to do so.

When I focused on trajectories and tried to map them, the forms and documents especially attracted my attention (Figure 4). I decided to conduct further interviews and asked which documents are used, what classifications are defined, how they are filled out, and how they

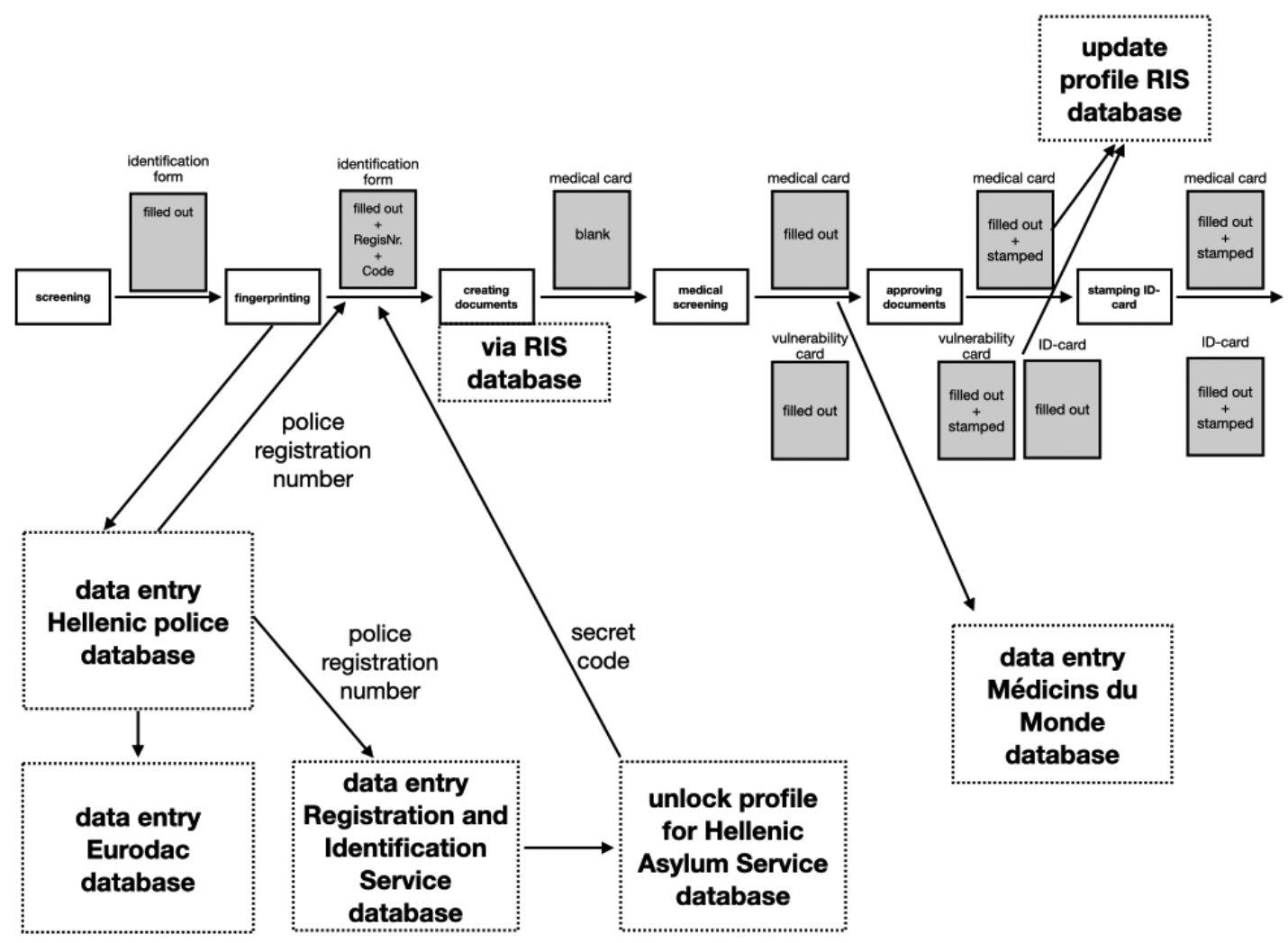

Figure 4. Trajectory map of the Registration and Identification Centre Moria. 
are used for data entries. The forms circulate between the different teams and distribute data to several organizations and their databases. The forms also coordinate the actions between Frontex, Hellenic police, RIS and MdM by transforming complex processes of collaboration into a simplified chain (Schüttpelz, 2013). Like in a relay race, the forms go from one hand to the next and initiate a new routinised practice with each delivery: When the filled-out identification form from the screening is given to the fingerprinters, the latter can create a profile within the Hellenic Police database and start fingerprinting; when the Hellenic Police database identification number and a secret symbol has been added on the identification form, the RIS clerk can create another database profile for her agency. Through the relay with forms, several data identities and a legalized ID-entity are crafted in a cumulative process.

Although the trajectory map shows how forms are crucial for the distribution of data and the simplification and coordination of collaboration among several agencies, it does not reveal the complexities of paperwork within administrations. As Garfinkel points out, reports within an institutional ecology are not written for outsiders but for entitled actors who are capable of reading their indexical and cursory texture and relating those to particular working contexts (Garfinkel, 1969, p. 201). This is why the investigator has to focus on various usercontexts and carve out the multiple ways clerks work with reports. Taking this into account, I tried to work out what the forms do in each work setting. For instance, as a purification device (Latour, 1993), the identification form leaves out all the messiness as well as all the objections from the arrivals and creates a case out of predefined classifications that can be easily processed in a later step. The identification form, the restriction of the liberty card, and the medical card additionally authenticated the (new) identity of an arrival and address responsibility to a state agency after they have been signed and stamped. With this, they ascribe a stigma to its carrier (van der Ploeg, 1999). The forms are also used as a device of social sorting (Bowker \& Star, 1999). At the end of the identification and registration process, the RIS creates referring documents that are sent to other Hellenic agencies via email. While identities with the item "Willingness of applying for Asylum: No" are sorted into the category "Non-Asylum Applicant" and forwarded to Hellenic police, identities with the item "Willingness of applying for Asylum: Yes" are sent to the Hellenic Asylum Service or those classified as vulnerable go to E.K.K.A. and after being archived by RIS, the forms become a warrantor of an identity and that an administrative procedure has taken place. This backup also entails the basic personal information of an arrival for potential future needs.

Observing the trajectory map that guided my inquiry also made me uncomfortable in another way. It somehow assumes that translation happens successfully and smoothly and leaves frictions and failure aside. Work in the realm of ANT has repeatedly pointed out that transla- tion and betrayal are two sides of the same coin (Callon, 1984). With a focus on betrayal and failure, I noticed that the interplay of different forms and databases made the job of the fingerprinter a severe test. The database system of Hellenic Police is basically software used in many countries and also usually available in English. The adaption to the administration of Hellenic police included, among other things, that it has been translated into Greek and only Greek. However, it is not Hellenic police officers but Frontex officers who are entering the data into that database-and most of them are neither able to speak Greek nor to read Greek letters. The identification form they receive from the Frontex screeners again is usually filled out in English. In this way, Frontex fingerprinters are turned into bad translators who produce potentially error-prone data and other overflows.

To make translation more stable, Hellenic police has printed out additional sheets with the translations of the most relevant categories and items from the identification form as well as from the Hellenic database. The Frontex fingerprinters in turn tried to learn how to correctly enter data by memorizing the running order of clicking through the system. However, the Hellenic police database is not a silent and passive entity. If there is a wrong click, for instance, it returns an error message. It also cross-references the data entries with all the others saved in the database and creates a list with similar names and gives some additional alerts. This overstrained the Frontex officers, which is why they went to the Hellenic police officers' container and asked for help. As most of the times the database produces false alerts, both Frontex and Hellenic officers became reluctant to check on them and started to ignore them. This mode of ignorance, however, may produce all kinds of data-errors that could also have unforeseen consequences for the people those datasets are about.

\section{Articulating Issues, Keeping Them Contestable and Bringing Them to Other Arenas: Issue Maps}

In the previous sections, this article developed various maps of the socio-technical assemblage of the Moria hotspot that reject the reification of "big pictures" created by EU and EU state agencies loaded with visions of technocratic border management, a good collaboration between state agencies and lawful and a seamless bureaucratic procedure. The article suggested studying the interactions between human and non-human entities with situational maps, to work out the tensions of collaboration among different collectives as well as the enactment of a 'human multiple' by social world maps, and to trace the circulation of forms and data by trajectory maps. In this last section of the article, I will collect and generalize various issues and create what I call an issue map (Figure 5).

Clarke uses positional maps to disentangle contested or debated issues and to analyse the positions of the spokespersons taken in a particular public discourse. 


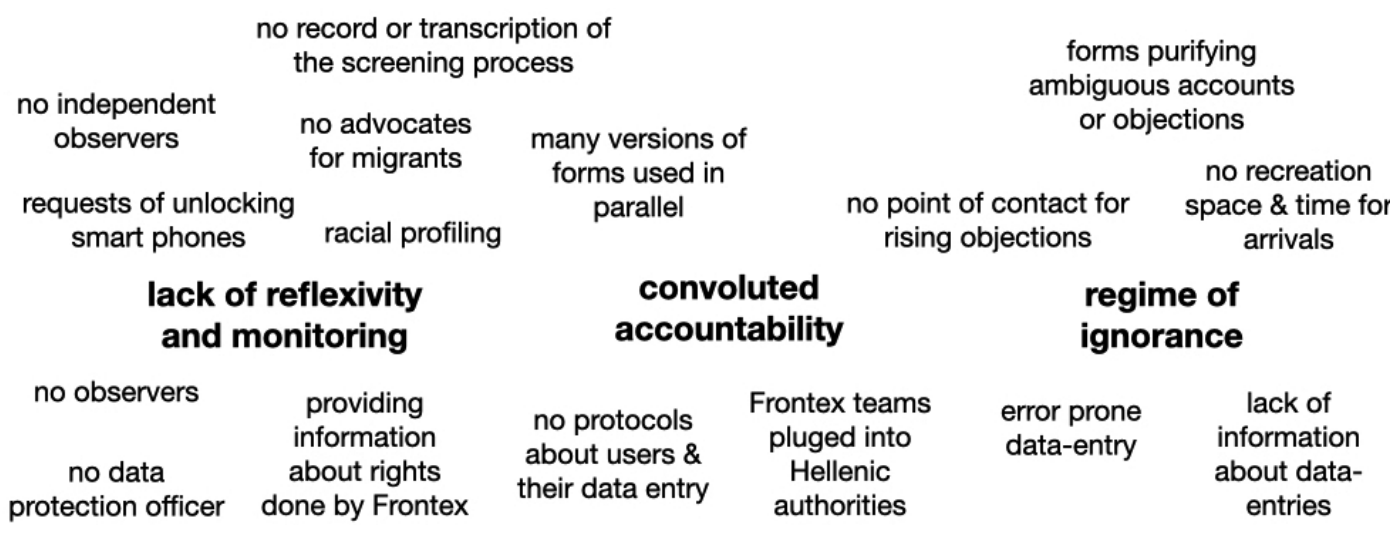

Figure 5. Issue map of the Registration and Identification Centre Moria.

Within institutional ecologies of border control, which is better characterised by secrecy, barriers and caution than by public debates and controversies, a discourse analysis is difficult to conduct. But Clarke also stresses to be sensitive to the issues which are somehow there but remain absent, as well as to look out for contradicting accounts and positions actors that are articulating (Clarke, 2005, p. 129). This might be a more suitable starting point for a critical approach of issue mapping that focuses on power relations and conditions of governing and produces silenced, invisibilized and othered voices and positions. In the following, I will articulate different issues by interrelating and generalizing topics that came up throughout the inquiry and the different mapping processes.

First, several orderings work hand in hand and enact a regime of ignorance: The socio-material arrangement does not provide any workplace for complaints and appeals; forms in use do not document how data has been gathered in the very processes of interrogation and screening but merely state a purified version about the case; advocates speaking in favour of migrants are absent; several data-entries are conducted without letting migrants know; or wrong data entries with unforeseen consequences are ignored. Furthermore, different orderings co-produce what I call convoluted accountability. Data entries into the Hellenic police database are conducted by Frontex personnel without leaving a trace; the practice of identification and registration is carried out by Frontex personnel although the Hellenic state authorities take responsibility; and different versions of formulas created by different staff circulate the Moria hotspot and create a mess. Moreover, there is a severe lack of reflexivity through the absence of monitoring devices or third parties. No independent party checks on human rights and legal issues, if the actions of the officers comply with legal requirements, or on data quality, protection, and privacy issues when data is gathered and exchanged between several databases.

Although I think that the generalization of those issues is valid, it makes me feel unease. While the former mapping strategies assembled accounts quite closely to my interlocutors, this move makes me critique them from a separated academic 'space of expertise.' Furthermore, such big labels risk being cut from the grounded accounts. So how to articulate critique that remains situated, that keep its relation to the accounts of the interlocutors alive, and that remains contestable not only to other colleagues from academia but also to other arenas?

Praxeographic work has pointed out that research is not only about tracing but also about making new associations by starting co-laborative forms of knowledge production. This, however, requires "mutual willingness and interest of the various parties to be inspired...by each other's practices" (Zuiderent-Jerak, 2010, p. 700)something which appears to be almost impossible in an institutional ecology of migration and border control and especially in the Moria hotspot. Access is very limited and the situations that the researcher observes are highly asymmetrical. Restrictions of information are everywhere, confidentiality agreements have to be signed, and the employees are overworked to their limit and frightened by the lack of information that fuels the already scandalized and scandalous discourse about Moria. Regardless of the existence of a co-laborative project, the researcher would face the problem of having quite limited room for manoeuvre and running into the danger of getting instrumentalised and being accused of becoming a 'system designer.'

An alternative could be to reach out to other social worlds and arenas instead. Issues concerning the exchange and gathering of data, for instance, could be shared with data monitoring and data protection actors from civic society (e.g., algowatch), from state administrations (e.g., data protection officers in Germany) or the EU (e.g., the European Data Protection Supervisor). Bringing issues to other arenas would not only make them contestable but also rearticulate them due to different practices. The issues worked out by the researcher may be interesting to her and a particular research community but perhaps not so much for collectives being concerned with, and working on legal human rights, policy, data protection or other issues. In this sense, 
critiquing could be an on-going and collaborative process of bringing new and more values than truth to the table and (re)position the researcher's work in new actor-networks.

Issues may also be re-appropriated regarding new agendas, e.g., to a political initiative on data protection rights. In this way, such forms of collaboration would not only invert the issue map, the critique of the researcher and her positioning, but also convert them into something else. Such work on producing new hybrid and contestable forums have their own complexities, struggles and pitfalls and raise issues of participation, positioning and negotiation that are beyond of this article (Farías, 2016). Still, it would be a way to "articulate possibilities of other worlds" (Law \& Singleton, 2013, p. 500)-even in such rigid institutional ecologies as European migration and border control.

\section{Acknowledgments}

An earlier version of this article was presented the panel "Following What, When and Where to? Reflecting on Mobile Methods in Migration Research." The panel was part of the conference "A Mobilities Lens to the Human Mobility-Environmental Change Nexus" at Wageningen University in 2019. The author is grateful to the participants, as well as to the guest editors Kolar Aparna and Joris Schapendonk, to the anonymous reviewers and to the digital media lab at MCTS for their very helpful comments. Finally, the author thanks all the informants who supported the fieldwork.

\section{Conflict of Interests}

The author declares no conflict of interests.

\section{References}

Bowker, G. C., \& Star, S. L. (1999). Sorting things out: Classification and its consequences. Cambridge, MA: MIT Press.

Callon, M. (1984). Some elements of a sociology of translation: Domestication of the scallops and the fishermen of St Brieuc Bay. The Sociological Review, 32(1), 196-233.

Callon, M. (1998). An essay on framing and overflowing: Economic externalities revisited by sociology. The Sociological Review, 46(Suppl. 1), 244-269.

Campesi, G. (2018). Seeking asylum in times of crisis: Reception, confinement, and detention at Europe's Southern border. Refugee Survey Quarterly, 37(1), 44-70.

Clarke, A. E. (2003). Situational analyses: Grounded theory mapping after the postmodern turn. Symbolic Interaction, 26(4), 553-576.

Clarke, A. E. (2005). Situational analysis. Thousand Oaks, CA: Sage.

Clarke, A. E. (2019). Situating grounded theory and situ- ational analysis in interpretive qualitative inquiry. In A. Bryant \& K. Charmaz (Eds.), The SAGE handbook of current developments in grounded theory (pp. 3-48). London: SAGE Publications.

Clifford, J. (Ed.). (1986). Writing culture. Berkeley, CA: University of California Press.

Consolidated version of the Treaty on the Functioning of the European Union, 2012/C 326/01 (2007).

Dalton, C., \& Mason-Deese, L. (2012). Counter (mapping) actions: Mapping as militant research. ACME, 11(3), 439-466.

Deleuze, G. (1986). Foucault. Paris: Editions du Minuit.

Dijstelbloem, H., \& Broeders, D. (2015). Border surveillance, mobility management and the shaping of nonpublics in Europe. European Journal of Social Theory, 18(1), 21-38.

Dimitriadi, A. (2017). Governing irregular migration at the margins of Europe. The case of hotspots on the Greek islands. Etnografia e Ricerca Qualitative, 1, 75-96.

EU Commission. (2015). Explanatory note on the 'hotspot' approach. Brussels: European Commission. Retrieved from https://www.statewatch.org/news/ 2015/jul/eu-com-hotsposts.pdf

Farías, I. (2016). Devising hybrid forums: Technical democracy in a dangerous world. City, 20(4), 549-562.

Garfinkel, H. (1969). "Good” organizational reasons for "bad" clinic records. In H. Garfinkel (Ed.), Studies in Ethnomethodology (pp. 186-207). Engelwood Cliffs, NJ: Prentice Hall.

Geertz, C. (1973). The interpretation of cultures. New York, NY: Basic Books.

Göde, B. (2015). Praktiken kartografieren. Was bringt Clarkes Situational Analysis für Praxeografien? [Mapping practices. How does Clarke's situational analysis contribute to praxeografies?]. In F. Schäfer, A. Daniel, \& F. Hillebrandt (Eds.), Methoden einer Soziologie der Praxis [Methods of a sociology of practice] (pp. 197-215). Bielefeld: transcript.

Halder, S., \& Michel, B. (2019). Editorial-This is not an atlas. In kollektiv orangotango+ (Eds.), This is not an atlas. A global collection of counter-cartographies (pp. 12-25). Bielefeld: transcript.

Haraway, D. (1988). Situated knowledges: The science question in feminism and the privilege of partial perspective. Feminist Studies, 14(3), 575-599.

Hess, S. (2010). 'We are facilitating states!' An ethnographic analysis of the ICMPD. In M. Geiger \& A. Pécoud (Eds.), The politics of international migration management (pp. 96-118). London: Palgrave Macmillan.

Knecht, M. (2013). Nach writing-culture, mit ActorNetwork: Ethnografie/Praxeografie in der Wissenschafts-, Medizin-und Technikanthropologie [After writing-culture, with actor-network: Ethnography/praxeography in the anthropology of science, medicine and technology]. In S. Hess, M. Schwertl, \& 
J. Moser (Eds.), Europäisch-ethnologisches Forschen. Neue Methoden und Konzepte (pp. 79-106). Berlin: Reimer.

Kuster, B., \& Tsianos, V. (2012). Thematic report "Border crossings" (WP4). Mig@Net. Retrieved from https://www.academia.edu/3372539/Thematic Report_Border_Crossings_WP_4_MIG_at_NET_ Vassilis_Tsianos_Brigitta_Kuster

Kuster, B., \& Tsianos, V. (2016). „Aus den Augen, aus dem Sinn“-Flüchtlinge und Migranten an den Rändern Europas. Hotspot Lesbos ["Long absent, soon forgotten"-Refugees and migrants at the margins of Europe. Hotspot Lesvos]. Heinrich-Böll Stiftung. Retrieved from https://www.boell.de/de/2016/08/ 03/hotspot-lesbos

Latour, B. (1993). We have never been modern (C. Porter, Trans.). Cambridge, MA: Harvard Univ. Press.

Latour, B. (2005). Reassembling the social: An introduction to actor-network-theory. Oxford and New York, NY: Oxford University Press.

Law, J. (2004). After method. London: Routledge.

Law, J., \& Ruppert, E. (2013). The social life of methods: Devices. Journal of Cultural Economy, 6(3), 229-240.

Law, J., \& Singleton, V. (2013). ANT and politics: Working in and on the world. Qualitative Sociology, 36(4), 485-502.

Mathar, T. (2008). Review essay: Making a mess with situational analysis? Forum Qualitative Sozialforschung/Forum: Qualitative Social Research, 9(2). http://dx.doi.org/10.17169/fqs-9.2.432

Mathar, T. (2010). Der Digitale Patient. Zu den Konsequenzen eines technowissenschaftlichen Gesundheitssystems [The digital patient. On the consequences of a technoscientific health system]. Bielefeld: transcript.

Mezzadra, S., \& Neilson, B. (2013). Border as method, or, the multiplication of labor. Durham, NC: Duke University Press.

Mol, A. (1999). Ontological politics. A word and some questions. The Sociological Review, 47(Suppl. 1), 74-89.

Mol, A. (2002). The body multiple. Durham, NC: Duke University Press.

Niewöhner, J. (2016). Co-laborative anthropology. Crafting reflexivities experimentally. In J. Jouhki \& T. Steel. (Eds.), Etnologinen tulkinta ja analyysi. Kohti avoimempaa tutkimusprosessia [Ethnological interpretation and analysis: Towards a transparent research process] (pp. 81-125). Helsinki: Ethnos.

Papada, E., Papoutsi, A., Painter, J., \& Vradis, A. (2019). Pop-up governance: Transforming the management of migrant populations through humanitarian and security practices in Lesbos, Greece, 2015-2017. Environment and Planning D: Society and Space. Advance online publication. https://doi. org/10.1177/0263775819891167

Pickles, J. (2004). A history of spaces: Cartographic reason, mapping, and the geo-coded world. London: Routledge.

Pollozek, S., \& Passoth, J.-H. (2019). Infrastructuring European migration and border control: The logistics of registration and identification at Moria hotspot. Environment and Planning D: Society and Space, $37(4)$, 606-624.

Rozakou, K. (2017). Nonrecording the "European refugee crisis" in Greece: Navigating through irregular bureaucracy. Focaal-Journal of Global and Historical Anthropology, 77, 36-49.

Schüttpelz, E. (2013). Elemente einer Akteur-MedienTheorie [Elements of an actor-media-theory]. In T. Thielmann \& E. Schüttpelz (Eds.), Akteur-MedienTheorie [Actor-] (pp. 9-70). Bielefeld: transcript.

Sørensen, E., \& Schank, J. (2017). Einführung [Introduction]. In S. Bauer, T. Heinemann, \& T. Lemke (Eds.), Science and technology studies. Klassische Positionen und aktuelle Perspektiven [Science and technology studies. Classical approaches and contemporary perspectives] (pp. 407-429). Berlin: Suhrkamp.

Star, S. L., \& Griesemer, J. R. (1989). Institutional ecology, 'translation' and boundary objects: Amateurs and professionals in Berkeley's museum of vertebrate zoology, 1907-39. Social Studies of Science, 19(3), 387-420.

Tazzioli, M. (2018). Spy, track and archive: The temporality of visibility in Eurosur and Jora. Security Dialogue, 49(4), 272-288.

van der Ploeg, I. (1999). The illegal body: 'Eurodac' and the politics of biometric identification. Ethics and Information Technology, 1(4), 295-302.

Zuiderent-Jerak, T. (2010). Embodied interventionsInterventions on bodies: Experiments in practices of science and technology studies and hemophilia care. Science, Technology, \& Human Values, 35(5), 677-710.

\section{About the Author}

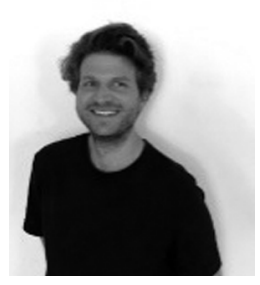

Silvan Pollozek is a member of the Digital Media Lab at the Munich Centre for Technology in Society (MCTS), Technical University of Munich. His research interests include digital infrastructures of Europe, logistics of contemporary migration and border management, and STS approaches to infrastructures, governance and mobility. 